\title{
Modeling of the process of the extinguishing gas concentration changes in the protected compartment
}

\author{
Przemysław Kubica ${ }^{1}$ and Sylwia Boron $^{1, *}$ \\ ${ }^{1}$ The Main School of Fire Service, Faculty of Fire Safety Engineering, 52/54 Slowackiego St., 01-629 \\ Warsaw, Poland
}

\begin{abstract}
The article discusses the aspect of the fire safety of rooms protected by Fixed Gaseous Extinguishing System (FGE-system). On the basis of a literature study, including the analysis of design standards, it was claimed that analytical models of gas outflow from the compartment ignore some parameters that can affect the process of extinguishing gas concentration changes in time. Correct prediction of the gas flow process may affect the retention time value, which is an important determinant of the fire safety of rooms protected by FGE-system. The density of extinguishing gas was indicated as a parameter with a large potential for extending the retention time. It was noted that the density of gas depends on atmospheric conditions like temperature, pressure and humidity, which are omitted in the standard models. In the research part, the concentration distribution of nitrogen and nitrogen-argon mixtures were analyzed using three methods. Obtained experimental data were compared with analytical calculations using a standard model (model $N$ ) and a new proposed model extended by an impact of the atmospheric conditions (model PK). Model $P K$ showed greater accuracy of determining the process of extinguishing gas concentration changes. The new proposed model might be a valuable tool for further analysis of gas flow through the room.
\end{abstract}

\section{Introduction}

In the design process of Fixed Gaseous Extinguishing System (FGE-system), analytical models are a tool used to describe the outflow of extinguishing gas from the protected room.

The following models are listed in the design standards:

a) model with a sharp interface between extinguishing gas and air, presented in NFPA $2001[1]$

b) model with a wide interface between the gas and air, presented in EN 15004 [2] and ISO 14520-1 [3];

c) model of continuous mixing of extinguishing gas with air, at a constant rate within the volume - valid for areas in which the air is constantly moving [1, 2, 3].

The main purpose of using the standard models is to determine the retention times of extinguishing gases. In terms of definition $[1,2]$, retention time (hold time) is the time of maintaining the concentration of extinguishing gas in a room above a set minimum * Corresponding author: sylwiaboron@op.pl 
concentration $\mathrm{c}_{\min }$ at set heights. The value of $\mathrm{c}_{\min }$ and the heights at which it should be maintained depend on the standard adopted for design. According to the standard used in Europe [2], the retention time is measured from the moment when the extinguishing gas design concentration is reached in the room, until the extinguishing gas concentration exceeds $85 \%$ of the design concentration at $10 \%$ and $50 \%$ and $90 \%$ of the room height. It has been noticed that the model with sharp interface understate the values of the retention time while the model with a wide interface gives the underestimated values [4].

The standard models have a character of approximate analyzes with different level of simplification of the description of extinguishing gas concentration distributions in space and time. The outflow of extinguishing gas from the room results from the difference between hydrostatic pressures inside and outside the protected space. This process is caused by the difference in density between extinguishing gas and ambient air. According to the methodology described in standards $[1,2,3]$, a constant air density inside and outside the protected space is assumed, amounting $1.202 \mathrm{~kg} / \mathrm{m}^{3}[1]$ or $1.205 \mathrm{~kg} / \mathrm{m}^{3}[2,3]$. The influence of atmospheric conditions on both air density and extinguishing gas density is omitted. While in the case of gases with densities significantly different from air density, when the protected room is located inside the building, it does not cause a significant error (error of $1-3 \%$ ), in the case of gases with densities close to air density the error may exceed $45 \%$ [5]. The extinguishing gas flow causes changes in the distribution of extinguishing gas concentrations in the room.

It should be noted that on the basis of a single parameter - the retention time, it is extremely difficult to obtain information about the gas flow process and predict changes in gas concentrations occurring inside the protected room. Therefore, it is necessary to develop the standard models and use them for research for wider time and spatial scales.

\section{Model of retention time determination extended by the influence of atmospheric conditions}

One of the recent achievements in the field of FGE-system design was the extension of the existing analytical model of determining the retention time, by taking into account the influence of atmospheric conditions on the density of extinguishing gases [6]. The model with a wide interface used in European standard [2] has been chosen for the tests, because the results obtained with this model provide safer conditions in comparison to the model with sharp interface $[4,6]$. Taking into account the influence of atmospheric conditions including the variability of temperature, pressure and humidity, it is assumed that the resulting change in gas density will be in the range corresponding to the conditions that may occur inside the building.

Because the density of the extinguishing mixture and ambient air density depend of the atmospheric conditions, the model can be extended to include their impact. In the model with a wide interface, the density of gas occurs in the equations $(5,7,8,9)$ and in the auxiliary variables $k_{2}, k_{3}, k_{4}$ (correspondingly in the variable $k_{2}$ as the ambient air density $d_{0}$, in the variables $k_{3}$ and $k_{4}$, as the air density $d_{0}$ and the density of the mixture of extinguishing gas-air $d_{m}$ ).

The density of the extinguishing gas-air mixture $d_{m}$, according to the equation (5), depends of the $d_{g g}$ extinguishing gas density, indoor air density $d_{{ }_{0}}$ and the initial gas concentration $c_{p}$. The density of extinguishing gas and air presented in equation (5) can be determined by equations $(3,4)$. Thus, the density of the extinguishing mixture and air will depend of the atmospheric conditions.

A set of equations describing the developed model with the influence of atmospheric conditions is presented below:

1. Density of extinguishing gas components equation $(1,2)$ : 


$$
d_{A r}\left(T_{w}, p_{r z}\right)=1.719 \cdot \frac{283.15}{1013.25} \cdot \frac{p_{r z}}{T_{w}}(1) \quad d_{N_{2}}\left(T_{w}, p_{r z}\right)=1.206 \cdot \frac{283.15}{1013.25} \cdot \frac{p_{r z}}{T_{w}}
$$

where:

$d_{A r}$ - density of argon at $T_{w}$ and $p_{r z}\left[\mathrm{~kg} / \mathrm{m}^{3}\right]$;

$d_{N 2}-$ density of nitrogen at $T_{w}$ and $p_{r z}\left[\mathrm{~kg} / \mathrm{m}^{3}\right]$;

$p_{r z}$ - real pressure (atmospheric pressure considering height above a sea level) $[\mathrm{hPa}]$;

$T_{w}$ - temperature inside the protected space $[\mathrm{K}]$;

1.719 - density of $\operatorname{argon}\left[\mathrm{kg} / \mathrm{m}^{3}\right]$ at $\mathrm{T}=283.15 \mathrm{~K}$ and $\mathrm{p}=1013.25 \mathrm{hPa}$ [2];

1.206 - density of nitrogen $\left[\mathrm{kg} / \mathrm{m}^{3}\right]$ at $\mathrm{T}=283.15 \mathrm{~K}$ and $\mathrm{p}=1013.25 \mathrm{hPa}$ [2].

2. Density of extinguishing gas equation (3):

$$
d_{g g}\left(T_{w}, p_{r z}\right)=d_{N_{2}}\left(T_{w}, p_{r z}\right) \cdot \frac{c_{N_{2}}}{100}+d_{A r}\left(T_{w}, p_{r z}\right) \cdot \frac{100-c_{N_{2}}}{100}
$$

where:

$d_{g g}$ - density of the extinguishing gas at $T_{w}$ and $p_{r z}\left[\mathrm{~kg} / \mathrm{m}^{3}\right]$;

$c_{N 2}$ - volume concentration of nitrogen in extinguishing gas $[\% \mathrm{v} / \mathrm{v}]$.

3. Density of air inside protected room equation (4)

$$
d_{0 w}\left(T_{w}, p_{r z}, \varphi_{w}\right)=\frac{p_{r z}}{T \cdot R_{p s}}+\left(1-\frac{R_{H_{2} O}}{R_{p s}}\right) \cdot \varphi \cdot E_{1} / 100
$$

where:

$d_{0}$ - wet air density $\left[\mathrm{kg} / \mathrm{m}^{3}\right]$;

$p_{r z}$ - pressure $[\mathrm{Pa}]$

$T$ - temperature $[\mathrm{K}]$;

$\varphi$ - relative humidity $[\%], \varphi=\mathrm{e} / \mathrm{E}_{2} \cdot 100[\%]$;

$e$ - current vapor pressure $[\mathrm{Pa}], \mathrm{e}=\mathrm{E}_{2} \cdot \varphi / 100$;

$E_{1}-$ maximum vapor pressure $\left[\mathrm{kg} / \mathrm{m}^{3}\right]$;

$E_{2}$ - maximum vapor pressure $[\mathrm{Pa}]$;

$R_{p s}$ - individual gas constant of dry air $[\mathrm{J} / \mathrm{kg} \cdot \mathrm{K}]$;

$R_{H 2 O}$ - individual gas constant of water vapor $[\mathrm{J} / \mathrm{kg} \cdot \mathrm{K}]$.

4. Density of extinguishing mixture equation (5):

$$
d_{m}=d_{g g} \frac{c_{p}}{100}+d_{0 w} \frac{100-c_{p}}{100}
$$

where:

$d_{m}$ - density of extinguishing mixture (extinguishing gas-air) $\left[\mathrm{kg} / \mathrm{m}^{3}\right]$;

$d_{g g}$ - density of extinguishing gas $\left[\mathrm{kg} / \mathrm{m}^{3}\right]$;

$d_{0}$ - air density $\left[\mathrm{kg} / \mathrm{m}^{3}\right]$;

$c_{p}$ - design concentration of extinguishing gas $[\% \mathrm{v} / \mathrm{v}]$.

5. Density of air outside the protected room equation (6):

$$
d_{0}\left(T_{z}, p_{r z}, \varphi_{z}\right)=\frac{p_{r z}}{T \cdot R_{p s}}+\left(1-\frac{R_{H_{2} O}}{R_{p s}}\right) \cdot \varphi \cdot E_{1} / 100
$$


6. Auxiliary variables $k_{2}, k_{3}, k_{4}$ equation $(7,8,9)$ :

$$
k_{2}=k_{1}\left(\frac{d_{0}}{2}\right)^{n} \quad \text { (7) } \quad k_{3}=\frac{2 g\left|d_{m}-d_{0}\right|}{d_{m}+d_{0}\left(\frac{F}{1-F}\right)^{1 / n}} \quad \text { (8) } \quad k_{4}=\frac{2\left|P_{p}\right|}{d_{m}+d_{0}\left(\frac{F}{1-F}\right)^{1 / n}}
$$

where:

$k_{1}, n$ - factors characterizing the leakage in the room, determined on basis of the door fan test;

$F$ - dimensionless ratio of the leakage in the lower part of the room to the total leakage area; $P_{p}$ - initial pressure difference between the protected room and the surroundings.

7. Retention time equation (10):

$$
t=\frac{V}{H_{0}} \frac{\left(k_{3} H_{0}+k_{4}\right)^{1-n}-\left(k_{3} H_{g r}+k_{4}\right)^{1-n}}{(1-n) k_{2} F k_{3}}
$$

where:

$t$ - retention time $[\mathrm{s}]$;

$H_{g r}$ - the height at which interface will appear after time $\mathrm{t}[\mathrm{m}]$;

$V$ - room volume $\left[\mathrm{m}^{3}\right]$;

$H_{0}$ - room height $[\mathrm{m}]$;

$F$ - dimensionless ratio of the leakage in the lower part of the room to the total leakage area; $k_{2}, k_{3}, k_{4}-$ auxiliary variables.

\section{Investigation of extinguishing gases concentration changes}

The aim of the study was to analyze the correctness of projection of the extinguishing gas concentration changes in a model test chamber using available analytical models.

The basis of the research part were experiments conducted by PhD P. Kubica as a part of his dissertation, due to the relationship of research topics [5]. Experimental data were used for validation of analytical models.

The experimental tests were carried out in a test chamber with dimensions $0.6 \mathrm{~m} \mathrm{x}$ $0.6 \mathrm{~m}$ and $2.0 \mathrm{~m}$ high (Fig. 1). The chamber was equipped with a fixed gaseous extinguishing system for inert gases, a multi-point gas concentration measuring device and a thermocouple grid enabling a multi-point temperature register.

Tests were conducted for two extinguishing gases indicated in standards $[1,2,3]$ and for two new proposed mixtures of argon and nitrogen with densities close to air density (Tab. 1). The standard gases were $\mathrm{N}_{2} \quad 100 \% \mathrm{v} / \mathrm{v}$ and mixture with composition $\mathrm{Ar}=50 \%$ $\mathrm{v} / \mathrm{v}-\mathrm{N}_{2}=50 \% \mathrm{v} / \mathrm{v}$ (designated according to the standard [2] relevant IG-100 and IG-55).

\begin{tabular}{|c|c|c|c|}
\hline No. & $\operatorname{Ar}[\% \mathrm{v} / \mathrm{v}]$ & $\mathrm{N}_{2}[\% \mathrm{v} / \mathrm{v}]$ & $\begin{array}{c}\Delta d^{1)}=\left|d_{m}-d_{0}\right|\left[\mathrm{kg} / \mathrm{m}^{3}\right] \\
\left(\mathrm{t}=20^{\circ} \mathrm{C}, \mathrm{p}=1013 \mathrm{hPa}, \varphi=0 \%\right)\end{array}$ \\
\hline 1. & 50 & 50 & 0.094 \\
\hline 2. & 0 & 100 & 0.018 \\
\hline 3. & 7.5 & 92.5 & 0.001 \\
\hline 4. & 6.9 & 93.1 & 0.002 \\
\hline
\end{tabular}

Table 1. List of extinguishing gases used in tests [own work]. 
$\Delta \mathrm{d}^{1)}$ - difference between the density of the extinguishing mixture and the air density, under standard conditions [2] [ $\left.\mathrm{kg} / \mathrm{m}^{3}\right]$;

$\mathrm{d}_{\mathrm{m}}$ - density of the extinguishing mixture (extinguishing gas in the design concentration and air inside the protected space) $\left[\mathrm{kg} / \mathrm{m}^{3}\right]$;

$\mathrm{d}_{0}-$ density of air $\left[\mathrm{kg} / \mathrm{m}^{3}\right]$.

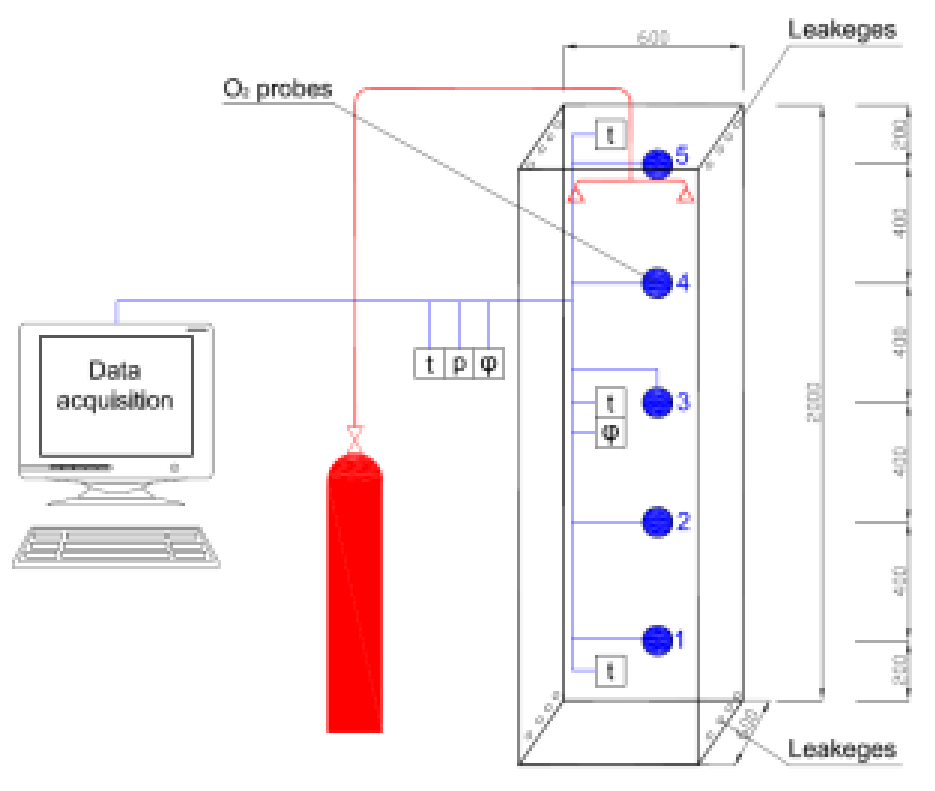

Fig. 1. The experimental setup [7].

The extinguishing gases were released to the test chamber. On the basis of the values read from the measuring devices, changes in the extinguishing gas concentration in time were determined.

The standard model $N$ and extended model PK were loaded into the "R" computer software in the form of appropriate scripts.

\section{Results and discussion}

In the comparative analysis of the results, data obtained using three research methods were used:

- experimental research carried out in the test chamber;

- calculations carried out using standard model with wide interface between extinguishing mixture and air [2] - model $N$;

- calculations carried out using the new model extended by the impact of the atmospheric conditions - (model PK).

The charts presented below are based on the values of concentrations read from the probe which presented the fastest gas concentration drop. Because model $N$ and model PK do not take into account the phase of extinguishing gas discharge, abscissa begins from 60 . $\mathrm{s}$ what corresponds to the moment after the end of the extinguishing gas release. 

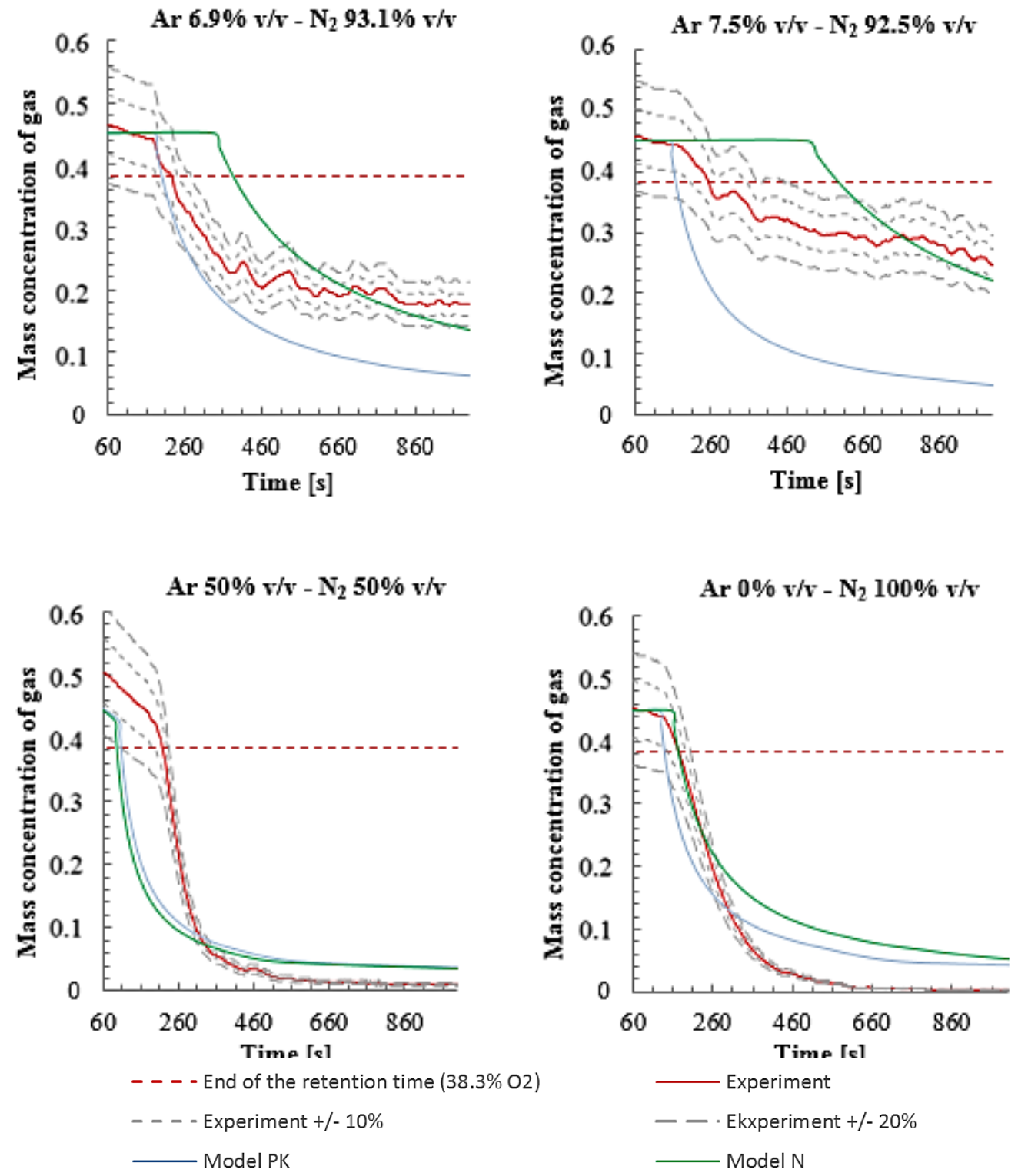

Fig. 2.Distribution of extinguishing gas concentrations obtained by experimental method, model $\mathrm{N}$ and model PK [own work].

Analyzing the graphs it can be stated, that definitely better results of using models were obtained during projection of the flow of gases heavier or lighter than air (IG-100, IG-55). Model $N$ and model PK predicted gas flow with good accuracy. The obtained graphs courses of both models were similar.

In case of extinguishing mixtures with a density close to air ( $\mathrm{Ar} 6.9 \% \mathrm{v} / \mathrm{v}-\mathrm{N}_{2} 93.1 \%$ $\mathrm{v} / \mathrm{v} ; \operatorname{Ar} 7.5 \% \mathrm{v} / \mathrm{v}-\mathrm{N}_{2} 92.5 \% \mathrm{v} / \mathrm{v}$ ), worse convergence of results was obtained. Moreover, larger discrepancies between model $N$ and model $P K$ were observed. Model PK predicted the distribution of gas concentration better than model $N$. In addition it was noticed, that in initial phase of gas flow better convergence of results was obtained. In later phase, the error 
of analytical models increased significantly with the drop of extinguishing gas concentration.

The analysis shows that the extinguishing gas concentration distributions obtained using model $P K$ satisfactorily correspond to the location of gas concentrations in experimental study. Modeled changes in gas concentration do not deviate from real values by more than $20 \%$ (and in most cases no more than $10 \%$ ), which can be considered as a good result. In some cases it was noticed that using model $N$, the drop of gas concentration started later in relation to the real values. Model $P K$ predicted start of gas concentration drop earlier than in reality. This approach ensures inference on the safe side.

As the second comparative parameter, the values of retention times of extinguishing gases determined using three test methods were used (Table 2). In most cases, model PK allowed to obtain results closer to the real values of retention times in relation to the values determined by standard model $N$.

Table 2. Determined values of retention times of extinguishing gases [own work].

\begin{tabular}{|c|c|c|c|c|}
\hline No. & Gas concentration & $\begin{array}{l}\text { Retention time } \\
\text { experiment } t_{R} \\
{[s]}\end{array}$ & $\begin{array}{c}\text { Retention time } \\
\operatorname{model} N \mathrm{t}_{\mathrm{RN}} \\
{[\mathrm{s}]}\end{array}$ & $\begin{array}{l}\text { Retention time } \\
\text { model PK } \mathrm{t}_{\mathrm{RPK}} \\
{[\mathrm{s}]}\end{array}$ \\
\hline 1. & $\begin{array}{c}\text { IG-55 } \\
\mathrm{Ar} 50 \% \mathrm{v} / \mathrm{v}- \\
\mathrm{N}_{2} 50 \% \mathrm{v} / \mathrm{v}\end{array}$ & 66 & 93.7 & 105.1 \\
\hline 2. & $\begin{array}{c}\text { IG-100 } \\
N_{2} 100 \% v / v\end{array}$ & 121 & 173.9 & 138.8 \\
\hline 3. & $\begin{array}{l}\text { Ar } 7,5 \% \mathrm{v} / \mathrm{v}- \\
\mathrm{N}_{2} 92,5 \% \mathrm{v} / \mathrm{v}\end{array}$ & 159 & 593.8 & 166.8 \\
\hline 4. & $\begin{array}{l}\mathrm{Ar} 6,9 \% \mathrm{v} / \mathrm{v}- \\
\mathrm{N}_{2} 93,1 \% \mathrm{v} / \mathrm{v}\end{array}$ & 116 & 385.1 & 200.8 \\
\hline
\end{tabular}

\section{Conclusions}

The paper presented the essence of a new approach to the design process of fixed gaseous extinguishing system and the effect of taking into account atmospheric conditions using model PK.

On the basis of the results it was found, that the retention time is not an excellent measure of the actual efficiency of gas mixtures, in particular for gases with densities close to air. Apart from the determined retention time value, the correct prediction of the moment at which the gas concentration changes starts is very important. Proper modelling of changes of gas concentration distributions is a wider source of information regarding the actual level of safety in a room protected by extinguishing gases.

For gasses with density close to air, analytical models are inaccurate. The obtained gas profile does not follow the model assumption. The stratification or gas self-mixing is not observed within the protected compartment [8].

Comparison of the results indicates model $P K$, as the one which gives more accurate description of the extinguishing mixture flow process. Especially, in case of gasses with a large difference in density relative to air, both the retention time and concentration distribution were predicted with better accuracy. 


\section{References}

1. NFPA 2001: Standard On Clean Agent Fire Extinguishing Systems Edition: 2012

2. EN15004-1:2008

3. ISO14520-1:2006

4. T. Hetrick, Fire Technol. 44, 239 (2008)

5. P. Kubica, W. Wnęk, Z. Tuzimek, A. Domżał, The influence of temperature, pressure and air humidity on the retention time of extinguishing gases (VII International Conference Fire Safety of Buildings, Warsaw 2012)

6. P. Kubica, Retention time of extinguishing gasses as a fire safety feature of compartments (Ph.D. thesis, Building Research Institute, 2014)

7. P. Kubica, L. Czarnecki, S. Boroń, W. Węgrzyński, Fire Safety J. 80, 1 (2016)

8. P. Kubica, W. Wnęk, Przem. Chem. 9, 1557 (2014) 